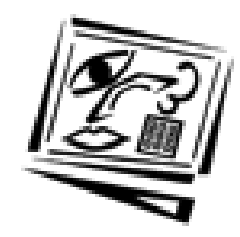

Australian Journal of Educational Technology

\title{
Technology in the School Curriculum
}

\author{
Dr Marlow Ediger \\ Professor of Education \\ Truman State University, Kirksville
}

There is strong emphasis placed upon use of modern technology in the elementary school curriculum. Technology is very strongly used in all facets of society, and elementary schools should not lag behind what is stressed in the societal arena. The elementary pupil of today will be expected to achieve in a heavily endowed work place involving technology. Many factories and farms have been strongly automated. Fewer workers are continually needed in these work places. Machines automatically do work that was formerly done with the use of human muscles and physical work.

Generally, people think of farming as stressing that very heavy manual labour is done continuously. Egg production, as one example, has eliminated most of the manual labour that was formerly done. As a high school student working at home after school hours and in summer, I pumped water by hand and carried it to the hen house, approximately seventy yards from the hand operated water pump. I carried buckets of feed from the barn to the laying house and put it in a feeder for the laying hens. I gathered eggs from the nests by placing the eggs in a bucket. The bucket became very heavy when gathering more and more eggs. Cleaning the hen house was indeed an undesirable chore. Presently with six hens in a cage and the cages being placed in rows, one person can take care of 15,000 laying hens readily, whereas I took care of 300 hens with a lot of manual labour involved. Today, the eggs fall down from the cages, onto a conveyor belt. A person at the end of the long row presses a button and all the eggs come down to where this worker is located. A machine is even available to pack the eggs into a crate. The feed goes down a conveyer belt every fifty minutes so that the laying hens have plenty to eat in order to produce eggs. The feed is augured automatically from a bin outside the laying house. Water also goes down the troughs continually for laying hens to drink. A truck comes to pick up the crates of eggs two times a week. The owner largely manages the laying house operation to see that all machines are working properly. 
Not all farm work by any means is automated to this extent. In contrast, any person who has cut, baled, and hauled hay realises the heavy use of muscles that are presently involved here.

Being a nonsmoker, I have observed at a cigarette factory where everything is automated including quality control. In other words, when the cigarettes have been packaged, the machine will cull out what was not done properly. Workers are there, few in number, to notice when involved machines are not working properly. They are then responsible for repair work when needed or to obtain assistance if someone else needs to do the work.

Menial work that requires human feats pays very little money, but even here the manual labour done by a human being is rather minimal, such as in fast food restaurants. At these fast food restaurants, there is a lot of movement and motion by workers in getting fast food orders fulfilled. No doubt, these workers get tired after being at the task, but the labour is not intensive.

When growing up on a farm, as mentioned above, farmers would shovel wheat by hand, since grain augers had not yet been perfected adequately. Shovelling grain by hand with a scoop is labour intensive. I became tired after shovelling fifty bushels of wheat from a pickup into a grain bin: there were many fifty bushel loads that needed shovelling in one day during harvest time. The grain auger took most of the human efforts out of shovelling wheat since the wheat was now augured rapidly, fifty bushels in three minutes, using an attached electric motor to the auger. What does this discussion have to do with the use of modern technology in the elementary school classroom?

\section{Personal beliefs about technology use}

There are selected criteria from the psychology of learning that need emphasis in having pupils work with technology. I believe that technology should capture pupil interests in learning. Activities here should be fascinating to engage pupil interaction. These interests should provide for effort in pupils desiring to achieve, grow, and develop. There is little time for misbehaviour if pupils are interested in the task at hand. I have noticed, for example, first graders who had little interest in drill and practice in arithmetic using paper and pencil. And yet when a hand held calculator or computer program was emphasised, these learners truly showed interest and fascination in learning. Interest is a powerful factor in learning since attention to the task at hand makes for increased achievement.

Second, I believe that technology may assist learners to perceive purpose in learning. If purpose is lacking, there will be little incentive for pupils to learn. Goal centred pupils achieve more than those who fail to perceive 
objectives in learning. I have observed many pupils who did not like to check long division problems using paper and pencil. Again, when the checking was done rapidly and accurately with the calculator or computer, there seemingly was even joy in doing the checking to see if the long division problem had been worked correctly. It appeared that pupils saw purpose, not drudgery, in checking these long division problems.

Third, I believe technology can assist pupils to attach meaning to ongoing lessons and units of study. What pupils learn then should make sense, not be nonsense tasks. There are numerous programs in computer use which guide pupils to achieve an objective. These numerous ways stress if one procedure is not understood, there are other approaches which will guide pupils to attach meaning. It is so important that pupils understand what is being learned. Many of us have learned that to divide fractions, we need to invert the divisor and then multiply. This mechanical procedure made no sense to me in grade school and in high school. There should be meaning in why 'the divisor is inverted and then multiply.' With clear illustrations together with the abstract numerals on the monitor, pupils may well understand and attach meaning as to why to 'invert the divisor and multiply.' What is learned should make sense and not merely be committed to memory.

Computer programs should assist pupils to perceive knowledge as being related, not in isolated bits. I noticed a delightful program on a monitor with high pupil enthusiasm working on the Egyptian system of numeration when studying a social studies unit on the Middle East.

Here, pupils were fascinated to learn that individual strokes represented the numerals from one through nine. Further interests were shown in the following features of the Egyptian system of numeration:

1. each heel bone of an ox, shaped like an arch represented a value of ten. Nine heel bones represented a value of ninety.

2. each coiled rope represented a value of 100 . There could be as many as nine coiled ropes to represent a value of 900 .

3. each lotus flower represented 1,000 . The pattern is that nine lotus flowers represent a value of 9,000 .

4. each bent finger represented a value of 10,000 . Nine bent fingers represent 90,000.

5. each tadpole represent 100,000; thus nine tadpoles represent 900,000.

I present this information, as an example, to show that computer programs along with other technologies can definitely assist pupils to perceive that knowledge is related. In this case, social studies and mathematics can definitely be related so that the learner perceives the interrelationship of subject matter. Morris and Pai (1976) wrote the following pertaining to Jerome Bruner's thinking on the relationship of knowledge: 
... since human beings seem to be able to store more information than they can spontaneously recall, the main problem in human memory is that of effective retrieval. Bruner is convinced that the key to effective retrieval is organisation of information. He contends there is sufficient evidence to support the assertion that, in general, any information organised around the interests and the cognitive structure of the learner can be most efficiently recalled. Hence, the only means by which we can reduce the quick rate of loss of human memory is to organise facts according the basic principles end concepts from which they were inferred. Further, 'the very attitude and activities that also seem to have the effect of conserving characterise figuring out or discovering things for ourself also seem to have the effect of conserving memory.' In addition to these effects, the learning experiences resulting from self-discovery give us an increased awareness of the connections and continuities between what we learn and what we do. As a result we are likely to see our activities in a broader context and thus gain more control of our acts in relation to an end in view. In learning by discovery, knowledge already possessed by the learner is used to gain new insights and, and in the process old knowledge becomes reconstructed.

Being very strong on learning by discovery, Jerome Bruner stresses organising information around the interests and cognitive structure of pupils. Discovery conserves or saves what has been learned previously. Pupils need to use knowledge to obtain new insights thus connecting what we learn and what we do. There are many key ides Bruner presents here for learners to relate knowledge and increase memory and recall. The use of technology such as video-tapes and software programs can and do assist pupils to relate knowledge inductively and thus retain content for a longer duration of time.

Fifth, the use of technology can certainly assist to provide for individual differences among pupils in terms of achievement in diverse academic areas. When pupils work on computer programs, they can definitely work at their optimal rate of achievement individually. Thus, in a tutorial program for example, pupils need to possess readiness factors such as having adequate background information. The learner then may move forward on that program at an as optimal rate as possible. Comparing this learning situation with viewing a videotape, the contents in the latter may move forward too rapidly or too slowly.

Sixth, technology and its use might well guide pupils to develop wholesome attitudes toward learning. Pupils seem to be fascinated with interacting with technology. I have observed pupils in classrooms with little interest in achieving in mathematics, as an example, until it is time for the learner to work with the computer. Here, the pupil interacted with drawing and abstract related numerals on the monitor. Problem solving was stressed here for a fifth grade pupil emphasising finding the volume 
of a cone. The drawings were sequential to permit the learner to determine the needed answer. Later, another pupil also came to the computer to solve additional problems cooperatively. The interest was high and the two learners worked together harmoniously. The joy that comes in working with others truly has its values for pupils.

\section{Philosophy of education and technology}

I am a strong believer in teachers, not only stressing the psychology of learning, but also the philosophy of education in technology use. There are selected philosophies that teachers need to understand and use in teaching-learning situations.

A first philosophy and its use I would like to discuss is experimentalism. Experimentalists believe strongly in a changing environment. Changes occur in all facets of the social natural environment. Rather rapid changes have occurred such as in technology. When I first started university teaching, there were no word processors on our campus. Typewriters were abundant. Electric typewriters quickly replaced the manual typewriters. Word processors rapidly replaced the electric typewriters. There is no manual or electric typewriter to be seen on our university campus today and even two decades previously! Changes can and do occur rapidly. There is hardly anything, objects as well as ideas, where change does not occur.

I have heard people say that their religious beliefs do not change. These do change very rapidly. I grew up in a General Conference Mennonite community and church. We had feet washing services after taking the bread and cup in communion services. Feet washing services have not been held for fifteen years in my former church. As a youth we had two couples that apologised in front of the church for having had premarital relations. These women had babies before nine months of marriage had elapsed. This procedure also has been eliminated some twenty years ago. What I am saying is that life's situations are continuously changing. Change is a key concept in experimentalist thinking.

With change, new problems arise. These problems need identification and delimitation so that they can be solved. An hypothesis is developed in answer to the problem. The hypothesis is tentative, never an absolute. Each hypothesis is to be tested in a lifelike situation. Problems, hypotheses, and tests of hypotheses are done in context within a practical situation. Experimentalism is utilitarian, not abstract nor theoretical. Pertaining to John Dewey and his beliefs on change, Ediger (1995) wrote the following:

John Dewey (1859-1952) lived during a period of rapid change. When he was born and even until the early 1900s, the automobile basically did not exist. When he died in 1952, manufactured automobiles, as a whole, were very dependable with hydraulic brakes, heaters and even a few with air 
conditioners. Electricity had its beginning in home and factory use in the early 1890s and was highly refined with its uses in 1952, with electric ranges, dishwashers, clothes washers, and driers. Changes have occurred from zero automobiles in 1859 to more highways and interstates being built to take care of the large number of automobiles in use in the present time. In 1859 horse drawn farm equipment was utilized to plow, harrow, disk, and seed the farm land. By 1952 farm tractors had electric lights, hydraulic brakes, and could pull a plow with four to five shears in plowing the land. Tremendous changes then occurred from 1859 (year of birth) to 1952 (year of death of Dr Dewey).

With these and many other changes, problems arise. Problems need identification and careful delineation in the school curriculum, as well as in society. Each problem is vital. Information acquired in school needs to be utilised to solve problems. Knowledge is not attained for its own sake, but is instrumental to the solving of identified problems. In society also, information is secured from a variety of reference sources, useful to solve each chosen problem.

From the data gathered, directly related to the problem, a hypothesis is developed. A hypothesis results for each identified problem. The hypothesis is tentative and subject to change through testing. Testing is done in a life-like situation. The results of the test may confirm or refute the hypothesis. Minor revisions of the hypothesis may also be needed. Generally, change will occur rather continuously.

Experimentalists believe that one can only know experience. One cannot know the real world in whole or in part as realists advocate nor does one know ideas only; of what exists out there in society, as idealists stress. With the world of experience as experimentalists believe, one identifies and solves necessary problems. Eichelberger (1989) wrote the following pertaining to pragmatism, also called experimentalism:

The relationship between knowledge and reality (truth) that is used by researchers today is that of the pragmatist, which states that all knowledge is produced by human beings and that we can never distinguish between knowledge and truth. In empirical research, this means that if something works in practice then it is true, or we can assume that it is true. A truth (knowledge) that is not supported by further empirical study will be modified or discarded.

How does any philosophy of education relate directly to the use of technology? I have noticed numerous computerised programs that are excellent for pupils to use in problem solving. Thus pupils in context have identified a problem for which they wish to have or find a solution. A software program carefully selected might well provide data to test a hypothesis. Generally, additional technological sources will be used to evaluate an identified hypothesis in answer to a problem. However, there are numerous programs which may provide information in the problem 
solving arena. Then too, there are simulated programs which tend to be lifelike and real. These entire software programs go through flexible steps of problem solving. A delightful computerised simulation is Choice or Chance (1984) which contains the following sequential content on the Age of Exploration:

Little is known of Hudson's life before his travels as an explorer began in 1687. During his sailing career, he sailed for both the Dutch and the English.

Hudson's voyages in 1687-1688 were founded by an English trading company, the Muscovy Company. His goal was never reached. In 1689 Hudson was hired by the Dutch East India Company, also a trading company, to lead another expedition. He again headed northeast hoping to avoid the ice floes. After the crew and supplies were in place, the ships set sail from Amsterdam, Holland on April 6, 1689. Their goal: find a northern route to Asia. Follow their journey (a relevant map is shown on the screen):

- Sail north and east to Nomya, Zemla, and an island in Russia.

- Crew threatens mutiny, but Hudson convinces them to sail southwest.

- Arrive at the coast of Maine and cut a mast for the ship on July 18, 1689. Some trading was done at that time. Sail south, along the coast to what is called the Chesapeake Bay. Arrived on August 3, 1689.

- Sail north along the coast to what is now called the Delaware Bay.

- Continue to sail north along the coast until a large inlet is spotted.

Imagine that you are Hudson. Use the map, called Dutch Exploration, to help you make decisions, consider the geographic factors presented and how they affect your decisions on the map page. You are now ready to sail upstream and explore. Good Luck! As you continue further into the inlet, a large island is seen. The island is covered with oaks.

Strong salt water tides occur. A suitable harbour with a depth of 5 fathoms is seen. The inlet is continually windy. Do you wish to
a. settle in this area?
b. explore further upstream?
c. return to Amsterdam?

Feedback is then given on the screen pertaining to choice(s) made. Additional content is presented so that new sequential decisions need to be made by students. The Choice or Chance simulation

1. relates history and geography.

2. brings reality into the program. 
3. emphasises active involvement on the part of learners.

4. presents background information to pupils before decisions are considered and made.

5. involves a logical sequence in that the programmers present sequential problems for pupils to consider.

6. stresses low risk on the pupil's part in interacting since the materials are not first hand, but are reality based.

\section{Idealism as a philosophy of education}

Previously, it was mentioned that experimentalists believe we can know experiences only from the physical and social world. Idealists state that we receive ideas only, not experiences; nor can we know what the real world is like in whole or in part as realists indicate. Idealism is an idea centred philosophy of education. Mind is real and needs to receive nourishment through quality ideas in different academic disciplines. There are numerous tutorial programs with computer use that stress learners achieving important concepts and generalisations. Knowledge objectives predominate, according to idealism as a philosophy of teaching and learning. Ediger (1986) wrote the following:

idealism is a more traditional approach in making decisions as compared to experimentalism and existentialism. According to Idealists, individualists cannot know the world as it truly is in terms of a objective reality. Each person, however, obtains ideas pertaining to objects and items in the environment. The mind brings order to what is observed and seen. Thus, of all facets of human development that is significant to develop, the mind or intellectual achievement must come first. Rich learning experiences will need to be in evidence to guide pupils to achieve maximum development mentally. Thus experiences may well be selected in terms of leading pupils to attain universal ideas and knowledge of the Absolute (God). These universal ideas need seeking and finding. Any person may not achieve perfect understanding of these universal ideas and of God. However, each person may continually move closer in achieving ideals of universal ideas and of the absolute.

From the thinking of idealists, the following implications apply for teaching and learning:

1. broad generalisations need emphasising that have much use to the learner in terms of mental and moral development.

2. quality ideals for pupils to emulate need adequate emphasis in the school curriculum.

3. intellectual objectives should receive primary stress in the curriculum.

4. quality coursework in literature and history, in particular, should guide pupils to achieve worthy generalisations.

5. abstract ideas are more important to emphasise as compared to the concrete and the semi-concrete. 
Key ideas in understanding idealism in teaching and learning are written by Bigge (1982) in the following statements:

The heart of idealism is the belief that basic reality consists of ideas, thoughts, minds or substantive selves, not physical matter. Since priority is given to minds, minds have bodies, but bodies do not have minds. Idealism usually carries with its view the ideas of the subsistence (the superexistence) of God, who also is basically mind or self. The universe is an expression of intelligence and will; its order is due to an external, spiritual reality. For idealists. people are just good-active substantive minds; they are absolutely real selves endowed with free will or genuine moral choice. This philosophy has ancient roots; it dates back to Socrates (469-399 BC) and Plato (427-347).

Idealism is really idea-ism. The source of this title is based on Platonic thought. For Plato, ideas alone were genuinely real; they consisted of immaterial essences. That which people perceive is a shadow of reality; each thing that they perceive gets its existence from its Thingness; an idea. A book is a book because of its being more or less an imperfect replica of Bookness. A woman is a woman because she is a replica of Womaness. Plato's assumed world of 'eternal verities' consisted of the True, the Good, and the Beautiful.

We can trace the development of idealism by listing some of the leading philosophers who contributed to this position and stated a leading idea that each has contributed to the philosophy. Socrates believed that children are born with knowledge already in their minds, but they need help to recall this innate knowledge. Plato contributed the idea of Ideas, which are the universal forms of all existing things and are the essence of reality. St. Augustine (350-430) held a dualistic (mind-body) theory of humanity within which the mind or soul is the set of the force of goodness.

What then are the implications of idealism for teaching and learning in the classroom involving computer use? I have seen selected excellent software packages which stress an idea centred curriculum. It seems as if for each academic area there are tutorials which might well assist any pupil to achieve subject matter knowledge.

These software packages should assist pupils to

1. achieve abstract content which is challenging and yet attainable.

2. learn content in depth with emphasis placed upon mental development of pupils.

3. acquire subject matter which makes sense and has meaning.

4. relate relevant content from an academic centred curriculum.

5. attain vital facts, concepts, and generalisations in each academic discipline.

An idea centred curriculum might also guide pupils to use what has been learned in problem solving. This belief assists in relating idealism with experimentalism. 


\section{Existentialism and the curriculum}

Existentialists are vary much concerned about the every day life and its anxieties of individuals. Individuals are concerned with choices that need to be made regardless if the desire is there to make these decisions. There is dread, fear, anxiety, and uncertainty in making choices. Many existentialists believe life to be absurd and ridiculous. There is dread in choosing when so many alternatives are available in the making of these choices. People do not live in a subject centred world, nor in a world of science. Rather they live in an open ended world where there are no standards in and of themselves. These standards, rules and regulations, need to be developed. Human beings make their own world; there are no absolutes nor are there given rules to live by. People, past and present, have developed standards to go by in life, but these are human made in an open environment where people, individually and collectively, develop the kind of society they wish to have. Pertaining to existentialism, Ozman and Craver (1990) wrote:

Because the individual human is so important as the creator of ideas, existentialists maintain that education should focus upon individual human reality. It should deal with the individual as a unique being in the world, not only as a creator of ideas, but as a living, feeling being. Most philosophies,... existentialists charge. tend to focus upon only as a cognitive being. The individual is this, but he is also a feeling, aware person, and existentialists think that this side deserves attention.

Which implications in the curriculum might follow some of the tenets of existentialism?

1. pupils individually need to choose freely, from among alternatives, those learning activities which are purposeful and meaningful.

2. content in the curriculum should reflect human feelings of loneliness, alienation, anxiety, and tension.

3. personal feelings of the pupil should be reflected in ongoing lessons and units of study. These feelings might well be expressed in art and construction projects, as well as of personal writings of learners.

The pupil needs to realise that choices do need to be made. If others make decisions for the personal self, choices are still being made, but the individual has abdicated responsibility in the decision making arena. Choices made do involve dilemma decisions, but authentic decisions must be made. Coercion is definitely not a part of the decision making philosophy of existentialists. Quality decisions made do not always make for good human relations. Alienation may also be an end result. The individual always needs to consider the consequences of choices made. Moral decisions made in a free environment is the goal of existentialists. Individuals should remember they are responsible for choices made; no one else can assume this responsibility. Choices are subjective, not objective by any means. 
With technology in the curriculum, existentialism advocates

1. individuals selecting from among others computer programs to complete. The individual should also choose which tasks to engage in when additional forms of technology are used.

2. the human condition with all of its uncertainties and anxieties should be stressed in the technology curriculum.

3. the pupil needs to have ample opportunities to study situations in which dilemmas are present. Decision making is not clear cut nor an absolute. Content in technology can emphasise these ideas.

4. the learner needs to express his or her feelings in diverse projects and activities. Thus a variety of writing experiences, fine arts and practical arts activities, speaking and reading learning opportunities, as well as listening may be stressed as evaluation techniques as well as enrichment activities in the technology curriculum.

5. heavy pupil involvement and choice in the technology curriculum should always be in evidence with existentialism as a driving philosophy in education.

\section{Realism and the technology curriculum}

Realists are strong advocates of individuals knowing in whole or in part what the real world is like. Their model comes from the world of science and mathematics. Precision and extreme accuracy are major tenets of realism as a philosophy of education. Thus the realist is strongly interested in having pupils achieve precise, measurably stated objectives in each curriculum area. With these kinds of objectives, carefully chosen by teachers and other educators, pupils do or do not attain each objective as a result of instruction. Learning activities selected by the teacher harmonises with what pupils are to learn as contained in the stated objective(s). Evaluation techniques need to be aligned with the stated objectives. Validity is then in evidence in testing and measurement. Reliability needs to stress test-retest, split half and / or alternative forms of appraisal. Results from pupil tests should indicate numerical data such as percentile ranks, per cent of items correct, standard deviations, quartile deviations, and standardised scores. Subjectivity in testing is definitely not wanted. Rather objectivity in testing is advocated to determine what any one pupil has learned as a result of teaching.

Pertaining to realism, Wild (1955) wrote the following:

The child, of course, should be interested in what he is learning. But it does not follow that whatever the child is interested in is, therefore, valuable. This is absurd. The skill of the elementary teacher lies in eliciting the interest of the child in the right things, especially in grasping the truth for its own sake. At the early stages no psychological or rhetorical technique should be neglected which is capable of strengthening this urge. When a mathematical principle has been understood, the child's attention should be drawn at once to the problem this enables him to solve. No opportunity should be lost to point out the principles of pure science which underlie modern technology. Language and grammar should be taught at essential 
phases of that mysterious process of apprehension by which the actual structure of things is mentally reflected and expressed, and by which such knowledge is achieved.

Realists do place very strong emphasis upon the following in teaching and learning situations:

1. carefully selected ends for pupils to achieve need to be written in precise, measurable terms.

2. learning opportunities chosen by the teacher align with the ends or objectives mentioned in number 1 above.

3. pupil achievement in having attained the precise objectives are measurable and presented in numerical terms.

4. the models of mathematics and science with its accuracy and specificity should be incorporated into the curriculum.

5. research studies can provide much data on what learners should study such as, for example, which words pupils should master in spelling. Many excellent studies have been made which indicate the words pupils use most frequently in functional writing. Words that are misspelled in these writings provide a scientific basis for determining practical words to be chosen by the teacher for pupil mastery.

Technology needs to be matched with the chosen objectives of instruction in lesson plans and units of study. After the use of technology in teaching and learning situations, the teacher may measure what pupils have learned. The results are given in numerical terms, not vague subjective data. The objective results may be reported to parents to indicate learner achievement in the school curriculum.

\section{Leadership in technology use}

Teachers need to be and are leaders in curriculum development. They select objectives, learning activities. and appraisal procedures. Teachers organise the classroom for instruction. Organisational work includes grouping pupils for instruction, disciplining pupils, as well as devising a schedule for teaching. Technology is definitely involved in making curricular decisions. For example, there should be an ample number of software programs in the learning activities section to guide pupils to achieve objectives. Definite leadership skills are necessary here. In addition to the classroom teacher, the principal plays a vital role in curriculum development.

Ritchie (1996) wrote the following pertaining to reasons why the use of technology is minimal in schools:

- A lack of administrative support

- inadequate staff development and technological support

- Low quantity, quality, and access of technologies in the classroom 
- Nonexistent or cursory plans for adopting and implementing technology into a school

- The failure to allocate a technology coordinator to help train teachers and coordinate the technologies

- A lack of funds and personnel to maintain equipment

- Continual assessment of content acquisition through traditional methods

- Establishment of a broad participatory clientele to establish a technology culture (Hoffman, 1996).

From the above statements, it is quite dear that school administrators need to understand and value technological use in the classroom. School administrators should perceive the necessity of implementing technology use in the classroom so that pupils may achieve more optimally. No doubt, there are school administrators who lack quality experiences with technology and therefore do not see the need for pupils experiencing learning activities involving technology. Each principal and supervisor should avail themselves in learning more about technology and how to integrate its use into the school curriculum. Talking to and learning from classroom teachers should assist the school administrator in realising the importance of technology in a modern elementary curriculum. Staff development programs in using technology in the curriculum should be in the offing. Teachers and administrators need to realise the importance of an updated curriculum. The school of today and the work place of tomorrow should not be in isolation from each other, but rather become integrated entities. Definite goals in inservice education using technology are musts. These goals and experiences for participants need to be chosen carefully. Relevance and importance are two concepts that need careful consideration when inservice education programs are developed and implemented. The goals of the workshop need to be clearly stated and should be cooperatively developed by workshop participants. There should be a large group session to hear a speaker or two who introduce vital inservice education goals. In the large group session, participants need to identify problem areas pertaining to the use of technology. Cooperative endeavours and committee work should follow to solve identified problems from the large group session. Consultants need to be available to assist in clarifying ideas and raising important questions to consider. A hands on approach should be in the offing. Individual endeavours need to also be pursued in the inservice education program. Participants individually have concerns that need addressing with consultant assistance. There should be opportunities to try out what has 
been studied in the inservice education program to the level of application in the regular public school classroom. Feedback from the classroom to participants in the inservice education program is a must!

There need to be definite plans to integrate technology into the school curriculum. This should not be left to chance, but rather quality goals and plans have been developed to use technology to its fullest in teaching and learning situations. Teachers need to have easy access to technology in lesson plan and teaching unit construction. A trained and educated coordinator of technology use can assist teachers to educate children for more optimal achievement. The coordinator of technology needs to develop good human relations with teachers with the latter having access readily to technology.

Adequate money needs to be budgeted and used to develop a curriculum with technology as a guiding principle. The lay public needs to be informed continuously about the merits of using technology in the classroom to assist each pupil to achieve as optimally as possible. The school culture reflects the importance of technology use with pupils, teachers, and administrators indicating its importance to child growth and development in the school setting.

Maskin (1996) wrote the following:

Promoters of computers in the classroom claim that exposing pupils to Web sites, email, and newsgroups promises more than the means of securing a job in the next century. Technology boosters also predict that the use and mastery of the Internet and the World Wide Web will produce affective changes that can be measured to produce increased student self-esteem and confidence. Whether working at home or in school, as an individual or in a cooperative learning or team setting, students will become 'infotectives', ie. independent thinkers, researchers, inventors, inquirers, capable of solving problems that often required the active direction of a teacher or supervisor...

In expanding the learning environment to include data bases, computer networks, and other library resources throughout the world. the Internet makes it possible for students to shape their own education. Once the easy accessing protocols are learned, the student can dive into these resources in the comfort of his or her home and/or library without the constant supervision and intervention of the teacher. Lao Tzui's dictum, 'He who teaches least teaches best,' describes a student centred teaching, learning, and assessment environment in which the student can access information from multiple perspectives and learn to use this information to solve complex problems.

Freedom, however, also opens up the possibility of choice. The emerging information technologies can just as easily be used to access sports trivia as they can explore issues being debated in Congress or at the World Bank. Many students, if left to their devices, might choose to spend hours surfing the 'Net for their own enjoyment rather than using it to complete a school 
assignment. The job of the teacher, therefore, is to involve students, individually or in teams, in Internet projects that are fun to do and skill enhancing. Students exposed early on to such educational endeavours we more likely to feel comfortable and confident in Drucker's knowledge based society...

I am convinced that Internet connectivity empowers students, gives them a research advantage, and generally gets them excited about learning.

We are truly in an information age in which there are so many outstanding sources of content for pupil acquisition. Pupils need to have ample opportunities to secure a variety of subject matter on a topic. It does cost money to have the latest of technology in our schools. But can we afford to be without it? Pupils today, in a few years, will be in the work place where the information age will even more be clearly defined as compared to today. Pupils of every race, creed, and religion must have the chances in an equitable manner to be able to use the latest in data securing sources. The upper income level pupils will have these opportunities of obtaining information through World Wide Web and Internet in the home setting. Other pupils also should have equality of opportunity to use state of the art sources to obtain information.

Pertaining to the future of technology, Mehlinger (1996) wrote the following:

Without going into detail regarding specific pieces of hardware, I can say with confidence that schools should expect more integration, interaction and intelligence from future technology. In their early days in school, computers and video were regarded as separate entities, and it was assumed they would stay that way. In fact, we can expect a continuing integration of these technologies. Voice, data, and images will be brought together into one package. One current example of this process is desktop video. In a single. relatively inexpensive unit, one has telephone (voice), computer (data storage and manipulation), and video (sending and receiving moving images) capabilities. Those who use the machine can talk to people at a distance, exchange documents, work collaboratively, and even see collaborators on the screen.

Technology will also become more interactive. In the field of distance learning, rather than strictly rely on one way video and two way communication, teachers and students will see another simultaneously, thereby making distance learning more like face to face classroom interaction. Computer based instruction will also be designed to respond to learners' interests and abilities, giving them greater control over what the need to learn and the pace at which they will learn it. And computer searches, which can be bewildering to the casual observer, will become easier and more responsive to what a user needs. Greater interactivity will make instructional programs even more powerful than they are today. 
Finally, technology will have greater intelligence. This intelligence will be displayed in several ways. First, the technology will have more features and greater capacity. Second, it will have the capability to learn from the user, so that it can customise its services to fit the user's learning style and interest. Future technology will provide not only data bases but knowledge bases. And technology will be able to stay abreast of that information most valued to the user and alert him or her to its availability.

Integration, interaction, and intelligence. These are three features we can expect of technology in the future. And they will change the way technology is employed in schools.

\section{In summary}

From the psychology of learning, there are numerous criteria recommended for teaching pupils. These are that interest needs to be developed within pupils for learning, purpose should be there on the learner's part to achieve, meaning should be inherent in ongoing lessons and units of study, relationship of knowledge is salient in the instructional arena, individual differences among pupils need to be provided for, and good attitudes need adequate emphasis.

Four philosophies of education were discussed and need to be appraised so that the best one(s) are used to meet individual pupil learning styles. These philosophies are experimentalism with its stress upon pupil problem solving; idealism with its emphasis upon an idea centred curriculum advocating learner's achieving abstract subject matter; existentialism with values placed upon the individual pupil selecting, from among alternatives, learning opportunities to pursue; and realism with its stress upon pupils achieving measurable stated objectives.

The future seemingly looks bright for use of technology in the classroom. The use of World Wide Web and Internet, email, faxing, and the electronic bulletin board, among others, will guide pupils to attain vital objectives of instruction. Desktop videos, as a truly modern device in technology, integrate voice, sound, and the pictorial.

\section{Selected references}

Bigge, Morris L. (1982). Educational Philosophies for Teachers. Columbus, Ohio: Charles E. Merrill Publishing Company, pp.25 and 26.

Choice or Chance (1984). Chicago, Illinois: Rand McNally and Company.

Ediger, Marlow (1995). Philosophy in Curriculum Development. Kirksville, Missouri: Simpson Publishing Company, pp.87.

Ediger, Marlow (1986). Social Studies Curriculum in the Elementary School. Third edition. Kirksville, Missouri: p.241.

Eichelberger, Tony R. (1989). Disciplined Inquiry: Understanding and Doing Educational Research. White Plains, New York: Longman, Inc., p.11. 
Hoffman, Bob (1996). School Technology Integration: An Automated Needs Assessment and Planning Tool. In Technology and Teacher Education Annual, edited by Robin, Price, Willis, and Willis. Charlottesville, Virginia: Association for the Advancement of Computing in Education.

Maskin, Melvin (1996). Infotectives on the Infobahn: Designing Internet-Aided Projects for the Social Studies Classroom. Bulletin of the National Association of Secondary School Principals, 80(582), 969.

Mehlinger, Howard D. (1996). School reform in the information age. Phi Delta Kappan, 77(6), 405-406.

Morris, Van Cleve and Young Pai (1976). Philosophy and the American School. Houghton Mufflin Company, p.378.

Ozman, Howard, and Samuel Craver (1990). Philosophical Foundations and Education, Fourth edition. Columbus, Ohio: Merrill Publishing Company, p.249.

Ritchie, Donn (1996). The administrative role in integration of technology. Bulletin of the National Association of Secondary School Principals, 80(582), 43.

Rose, Stephen A. and Phyllis Maxey Fernlund (1997). Using Technology for Powerful Social Studies Learning. Social Education, 61(3), 161-162.

Wild, John (1955). Modern Philosophies of Education. Chicago, Illinois: The National Society for the Study of Education, p.31.

Dr Marlow Ediger is Professor of Education at Truman State University, Kirksville (formerly Northeast Missouri State University), Route 2, Box 38, Kirksville, Missouri 63501 USA. (816) 665 2342, Fax (816) 627 7363. Dr Ediger is External Examiner of PhD theses for the University of Madras and Kerala, University of India. Member of Editorial Boards for Education, Reading Improvement, The Progress of Education (in India), The Educational Review, Experiments in Education, The Science Promoter, The Mathematics Teacher (in India), The Journal of English Language Teaching (in India), and Foreign Correspondent for the Himalayan Journal of Educational Research.

Please cite as: Ediger, M. (1996). Technology in the school curriculum. Australian Journal of Educational Technology, 12(2), 145-161. http: / / www.ascilite.org.au/ ajet/ ajet12/ediger.html 